\title{
Yenidoğanda Nadir Görïlen Bir Solunum Sıkıntısı olgusu: Kistik Adenomatoid Malformasyon
}

\author{
A Rare Cause of Respiratory Distress in Newborn: \\ Cystic Adenomatoid Malformation
}

\section{Mơhammet Mesut Neżi Engin', Önder Kiliçaslan', Oğuzhan Ay², Aybars Özkan ${ }^{3}$, Kenan Kocaba²}

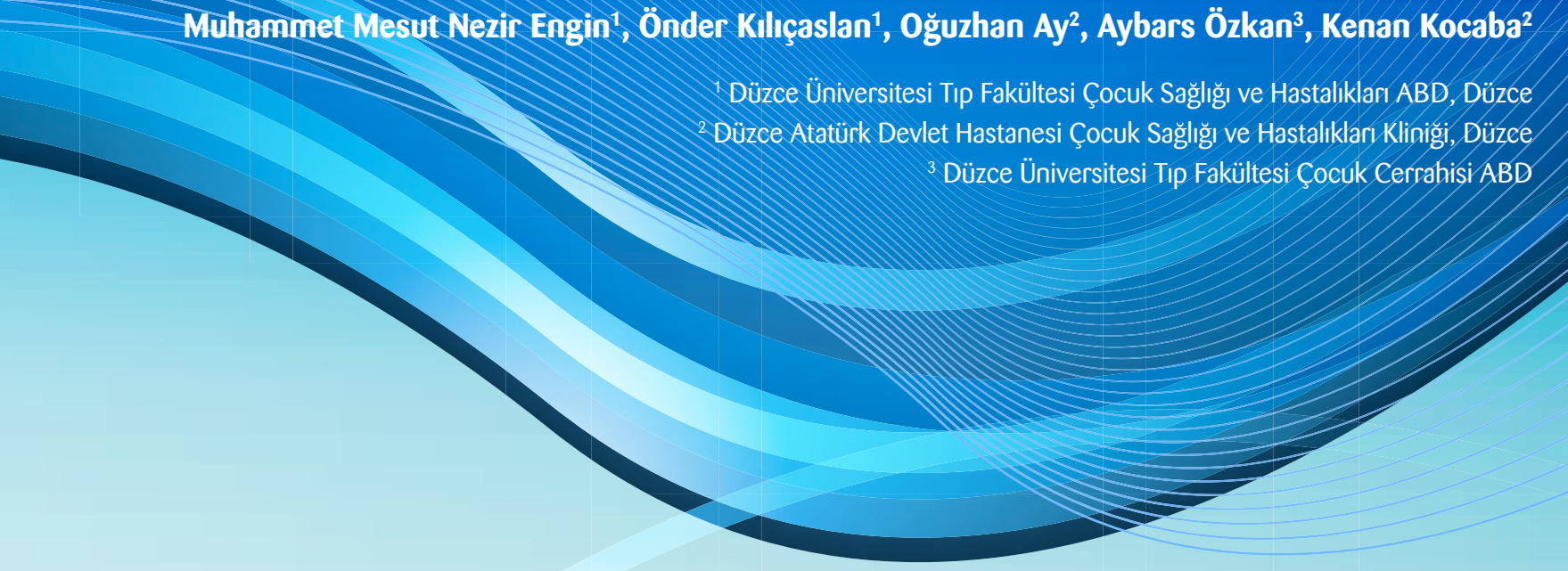

Correspondence / Yazışma Adresi:

Muhammet Mesut Nezir ENGiN

Düzce Üniversitesi Hastanesi Çocuk Hastalıkları Servisi Doktor Odası Düzce

Geliş Tarihi / Received : 22.08.2017

E-mail: doktormesut@hotmail.com

Kabul Tarihi / Accepted : 22.12.2017

\section{Özet}

Amaç: Konjenital kistik adenomatoid malformasyon (CCAM), displastik ve/veya hamartamatöz akciğer dokusunun, immatür bronş ağacından anormal dallanmasıyla oluşan, nadir görülen konjenital bir akciğer anomalisidir. İnsidansı 25-30 bin gebelikte birdir ve sıkııla erkek bebekleri etkiler. Bu vaka sunumunda nadir görülen CCAM'ın tartışıması ve hatırlatılması amaçlandı.

Olgu: Yirmi sekiz yaşında anneden 37. gestasyonel haftasında vajinal doğumla 2090 gr olarak doğan bebeğin 1 ve 5. dk. Apgar değerlendirmesi sırasıyla 9 ve 10 idi. Takiplerinde hipoglisemi gelişen ve beslenememe şikayeti olan hastanın Yenidoğan Yoğun Bakım Servisi'ne yatışı yapıldı. Yatışının altıncı gününde solunum sayılarının artmaya başlaması üzerine çekilen PA akciğer filminde sol üst lobda kistik görünüm izlendi. Tomografide sol akciğerde üst lobda, inferiora hafif uzanımıda gözlenen, en büyüğünün çapı yaklaşık 1,3 cm ölçülen birbirine yakın komşulukta multipl kistik oluşumlar saptandı. Kistik oluşumların boyutları $2 \mathrm{~cm}$ altında olması nedeniyle CCAM tip 2 ile uyumlu olarak değerlendirildi .

Sonuç: Yenidoğan döneminde etyolojisi saptanamayan solunum sıkıntısı varlığında nadir gözükse de CCAM akılda tutulmalıdır. Hayatın ilk dönemlerinde çekilen PA akciğer filmi doğal olarak değerlendirilse bile kistlerin içinde sıvı olabileceğinden tanı dışlanamaz. Kist veya kistlerin oluşturacağı etki ve klinik duruma göre cerrahi tedavinin ne zaman yapılacağına karar verilmelidir. ( Sakarya Tip Dergisi 2017, 7(4):251-255 )

Anahtar Kelimeler: Kistik adenomatoid malformasyon, Yenidoğan, Solunum sıkıntısı

\section{Abstract}

Aim: Congenital cystic adenomatoid malformation (CCAM) is a rare congenital lung anomaly which is charecterized by an abnormal branching of dysplastic or hamartomatous lung tissue from the immature bronchial tree. Its incidence is one of 25-30 thousand gestations and CCAM most commonly affects male infants. We aim to discuss and remind the rare CCAM with a case report

Case presentation: An (male, female) infant which had delivered at 37th gestational week from twenty-eight-year-old mother following vaginal delivery, his or her weight was $2.090 \mathrm{~kg}$. Apgar scores were 9 and 10 at 1 st and 5th min, respectively. Because of hypoglycemia and inability to feed, newborn was admitted to Neonatal Intensive Care Unit. A cystic formation was were 9 and 10 at 1 st and 5 th min, respectively. Because of hypoglycemia and inability to feed, newborn was admitted to Neonatal Intensive Care Unit. A cystic formation was
observed at the upper lobe of left lung on Posterior Anterior lung graphy which was taken due to the increasement of respiratory rate. Multiple cystic formations were observed in the upper lobe of the left lung in computerized tomography evaluation. These cysts were close to each other, slightly lengthened to inferior region and largest cyst was measured about $1.3 \mathrm{~cm}$ in diameter. Because of the size of the cystic formations was less than $2 \mathrm{~cm}$, this case was evaluated as type 2-CCAM.

Conclusions: In the presence of undefined neonatal respiratory distress, CCAM should be considered even if it appears as a rare disease. In spite of PA chest film taken in the early stages of life is evaluated as normal, the diagnosis can not be excluded because of cysts filled with fluid. Depending on the effects and clinical situations of the cysts, time of operation should be managed. ( Sakarya Med J 2017, 7(4):251-255 )

Keywords Newborn, Respiratory distress,Cystic adenomatoid malformation 


\section{Giriş}

Konjenital kistik adenomatoid malformasyon (CCAM), displastik veya hamartamatöz akciğer dokusunun, immatür bronş ağacından anormal dallanmasıyla oluşan, nadir görülen konjenital bir akciğer anomalisidir. ${ }^{1}$ Terminal bronşiyollerin aşıгı proliferasyonuyla karakterize içi silyalı ya da küboidal epitelle döşeli, multipl kistik yapılar ve fonksiyon göstermeyen akciğer dokusundan oluşur. ${ }^{2}$ İnsidansı 25-30 bin gebelikte birdir ve en sık erkek bebekleri etkiler. ${ }^{3} \mathrm{Bu}$ vakayla prenatal tanısı olmayan, yenidoğan döneminde hospitalize edilen, çekilen akciğer grafisinde kistik yapılar gözlenen ve bilgisayarlı toraks tomografisi (BTT) bulguları ile tanı alan,nadir görülen CCAM'ın tartışılması ve hatırlatılması amaçlandı.

\section{Olgu}

Yirmi sekiz yaşında anneden 37. gestasyonel haftasında vajinal doğumla 2090 gr olarak doğan erkek bebeğin1 ve 5 . dk. Apgar değerlendirmesi sırasıyla 9 ve 10 idi. Takiplerinde hipoglisemi gelişen ve beslenememe şikayeti olan hastanın Yenidoğan Yoğun Bakım Servisi'ne yatışı yapıldı. Ebeveynleri arasında bir akrabalık bulunmamaktaydı ve sağlıkı iki kardeşi vardı. Prenatal öyküde intrauterin gelişme geriliği dışında bir özellik yoktu. Fizik muayenede kilo:2090 gr (<10p), boy:45 cm(10-25p) ve baş:30 cm(<10p) olarak değerlendirildi. Hastanın genel durumu iyi ve sistem muayeneleri doğaldı. Hemogram, ALT, AST, üre, bun, kreatinin ve elektrolit değerleri normal sınırlardaydı. Yatışında bakılan kan kültüründe üreme olmadı. Hastanın yatışında ilk çekilen PA akciğer filminde sol üst lobda şüpheli retikülonodüler patern izlendi, solunum sistem muayenesi doğal olan hastanın takibine karar verildi (Resim 1).

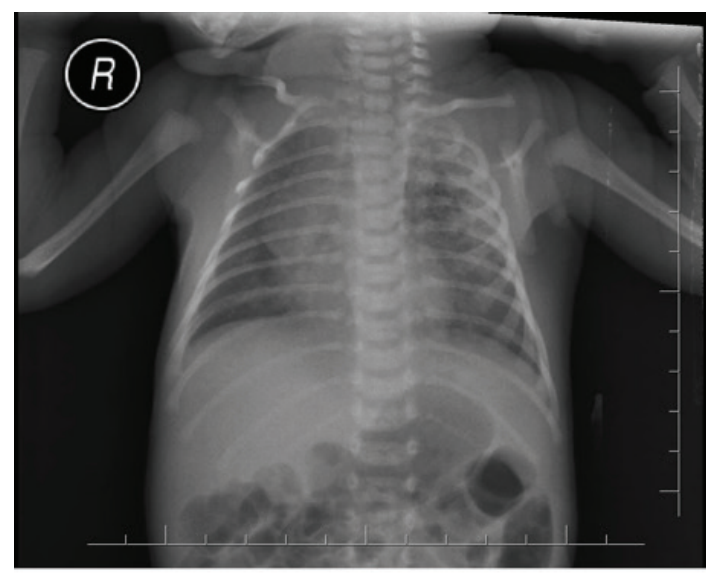

Resim 1 : Hastanın yatışında çekilen PA akciğer filmi
Hipoglisemileri düzelen hastanın yatışının altıncı gününde solunum sayılarının artmaya başlaması üzerine çekilen PA akciğer filminde sol üst lobda kistik görünüm izlendi (Resim 2).

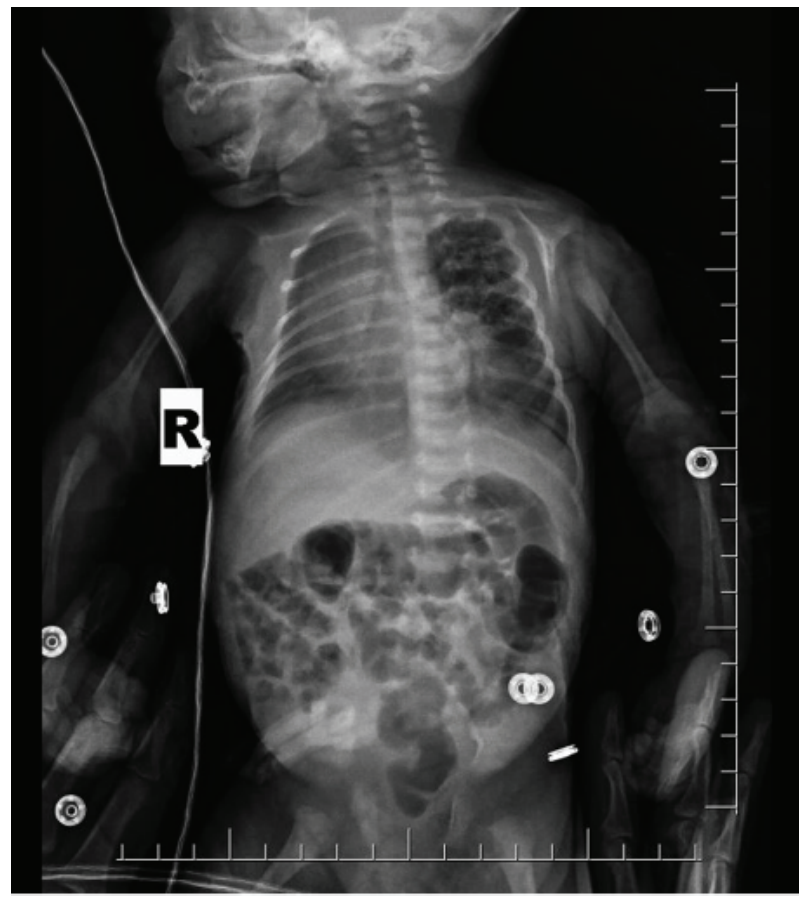

Resim 2: Hastanın yatışın 6. gününde çekilen PA akciğer filmi

Bu nedenle hastada, ayırıcı tanıda CCAM ve konjenital lober amfizem düşünülerek BTT planlandı. Tomografide sol akciğerde üst lobda, inferiora uzanımı gözlenen, en büyüğünün çapı yaklaşık $1,3 \mathrm{~cm}$ ölçülen birbirine yakın komşulukta multipl kistik oluşumlar saptandı. Kistik oluşumların boyutları $2 \mathrm{~cm}$ altında olması nedeniyle CCAM tip 2 ile uyumlu olarak değerlendirildi (Resim 3).

Olgumuzda takipne (Dakika Solunum Sayısı:88/dk) dışında bulgu yoktu. Hastanın genel durumu iyi, beslenmesi aktif ve aspirasyon öyküsü bulunmadığı için literatür bilgileri ışı̆̆ında düzenli takiplerle birlikte 5. ayında cerrahi girişim planlandı.

\section{Tartışma}

Literatürde konjenital akciğer defektleri ile ilgili ilk yayın, 1639'da Fontanus tarafından bir bebekte saptanan akciğer kisti vakasıdır. ${ }^{4}$ CCAM pulmoner dokuda primer gelişimsel bir defekt olup, 5-6 gebelik haftasında bronşioalveoler maturasyonun duraklaması ve 
mezenşimal hücrelerin aşııı çoğalması ile meydana gelen hamartomatöz bir patolojidir. ${ }^{5}$ ilk defa Chin ve Tang tarafindan 1949 'da diğer akciğer kistik lezyonlarından ayrı olarak tariflenmiştir. ${ }^{6}$

CCAM, vakaların \% 80-85'i solunum sıkıntısı nedeniyle yenidoğan döneminde veya yineleyen solunum yolu infeksiyonları nedeniyle iki yaşın altında görülebileceği gibi, yıllarca asemptomatik kalabilir. Solunum sıkıntısının şiddeti lezyonun boyutuyla orantılıdır. Tipik bulgular inleme, takipne ve çekilmeler ile artan solunum çabası ve siyanozdur. ${ }^{4}$ Erkeklerde daha sık olup, herhangi bir lobda yer kaplayabilir. Tek lobun tutulma riski \%95 iken, bilateral olarak görülme sıklı̆ı \%2'dir ${ }^{5}$. Bizim olgumuzda da takipne mevcuttu, tek lob tutulmuştu ve erkek bebekti.

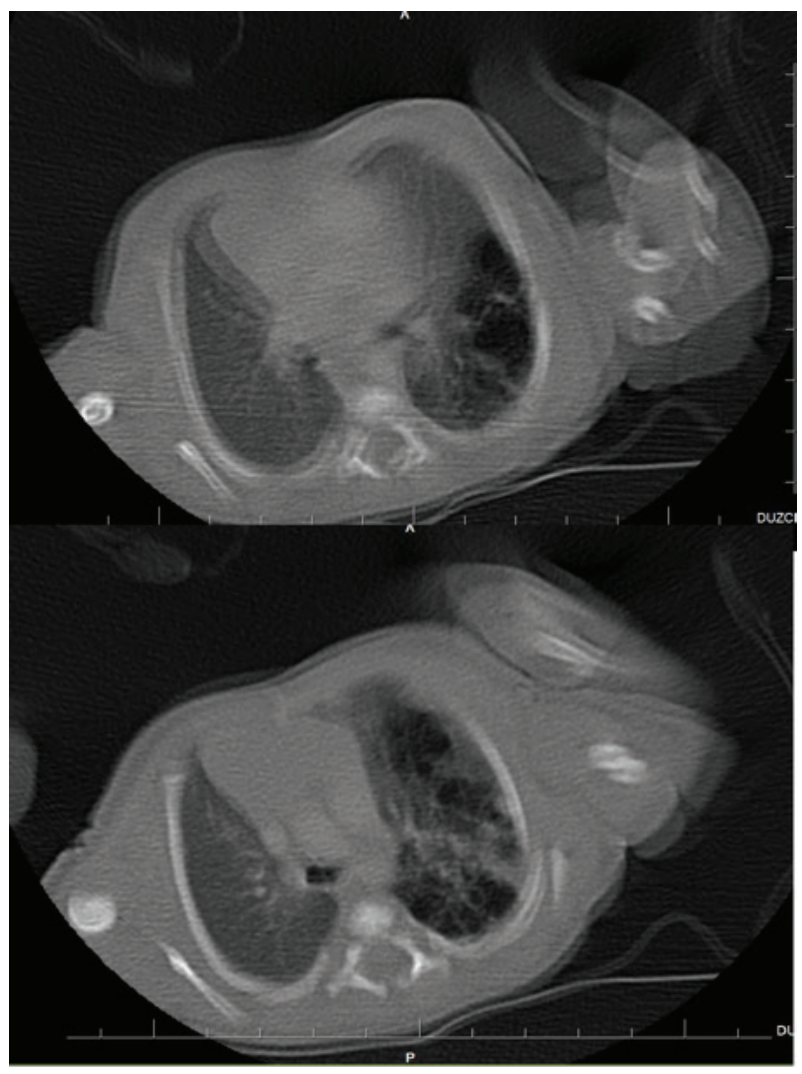

Resim 2: Hastanın çekilen bilgisayarlı tomografisi

Stocker ve arkadaşları tarafından CCAM 1977'de üç alt tipe bölünmüştür. Tip I'de prognoz en iyi iken, Tip III'te en kötüdür. Tip I ve II malformasyonların intrauterin gerileme gösterebileceği de bildirilmiştir ${ }^{8}$. Tip I formu \% 50-70 oranında görülür, bir veya bir- den fazla büyük (> $2 \mathrm{~cm}$ ) kistlerden oluşur. Kistler düz veya küboid hücrelerden meydana gelir,sıklıkla mediastinal herniasyona yol açarlar. Kistlerin duvarlarında belirgin düz kas ve elastik doku bulunur. Ara sıra mukus üreten hücreler görülür ve kıkırdak varlığı son derece nadirdir. Tip II formuna \% 15-30 oranında rastlanır, birden fazla küçük $(<2 \mathrm{~cm})$ kistlerden oluşur. Kistler duvarı silyalı küboidal veya kolumnar epitel ile döşelidir. Mukus hücreleri ve kıkırdak görülmez. Bu tip genellikle diğer sistem anomalileriyle birliktelik gösterir. ${ }^{6}$ Bunlar arasında, trakeoözofageal fistül, bilateral renal agenezi veya disgenezi, özofagus atrezisi, barsak atrezisi, diyafragma, kalp, merkezi sinir sistemi ve kemik anomalileri sayılabilir. Malignite gelişimi için risk altında değildir. Genellikle küçük olduğundan, komşu akciğere kitle etkisi yoktur. Tip III en ağır formudur ve \%5-10 oranında bildirilmiştir. Lezyonlar büyük ve tüm akciğeri tutabilir. Ayrıca fetal hidrops ve pulmoner hipoplazi tipiktir. Bebekler ölü doğmuş ya da doğumdan hemen sonra şiddetli, progresif solunum sıkıntısı, siyanoz ve solunum yetmezliği gelişmiş olabilir. Neredeyse tüm hasta bebekler erkektir., ${ }^{4,9}$ Stocker bu sınıflamaya 2002 'de iki tip (tip 0 ve IV) ekleyerek değiştirmiş ve lezyonu konjenital pulmoner hava yolu malformasyonu (CPAM) olarak yeniden adlandırmıştır. Trakeobronşiyal orijinli tip 0 , küçük ve fonksiyonel akciğerlerle normal bir görünüme sahiptir. Distal asiner kökenli Tip IV, çok büyük $(>10 \mathrm{~cm})$ kistlerden oluşur. Yenidoğan döneminde genellikle pnömotoraks ile ortaya çıkabilir. ${ }^{9,10}$ Bizim olgumuz tip II olarak değerlendirildi. Eşlik edebilecek patolojiler açısından çekilen trans fontanel USG sonucunda kranial patoloji saptanmadı. Toraks ve üst batın BT'de CCAM dışında görülebilen kesitlerde böbrek anomalisi ve ek anomali görülmedi. Kardiak anomaliler açısından patoloji gözlenmedi.

Hastalığın tanıSı prenatal dönemde fetal USG ile konulur. USG'de kistler, fetal hidrops saptanabilir. Ayırıcı tanı da prenatal MR, konjenital diyafragma hernisinden ayrımda yardımcı olabilir. Postnatal dönemde tanıda BTT yardımcıdır. Kistik lezyonların görüldüğü tipik bulgular tomografide mevcuttur: Tip I tamamen hava veya hava-sIvı seviyeleri içerir, çoğunlukla tek bir lezyon ya da birkaç büyük kist vardır. Tip II, tip l'e benzer bir görünüme sahiptir. Fakat, tip II'de lezyonlar daha çok sayıda ve küçük kistler içerir. Tip I genellikle katı, büyük ve homojen bir kitle olarak görülür. Kitle etkisi nedeniyle genellikle tek taraflı akciğer hipoplazisi ile karşı tarafa mediastinal 
şift vardır. Tip 4 doğumda veya çocukluk döneminde tansiyon pnömotoraks, enfeksiyon ile ya da rastlantısal olarak saptanır. ${ }^{4}$

Hayatın ilk dönemlerinde bu kistlerin içi sıvı dolu olduğundan direkt grafide homojen dens görünümler olabilir. Bu sıvilar bronşiyal, lenfatik ve dolaşım sistemi tarafından emilerek kistler radyolusen hale gelirler. $1^{1}$ Bu sebepten ötürü yaşamın ilk dönemlerinde çekilen direkt grafilerde bulgu vermeyebilirler. Bizim vakamızda da yatışta ilk çekilen PA akciğer filminde sol üst lobda şüpheli retikülonodüler patern izlendi (Resim 1). Takipne bulgusunun ilk günlerde olmayıp 6.günden sonra olması dikkatimizi çekmiştir, bu durumun CCAM patogenezi üzerine yapılacak daha ileri çalışmalar için önemli bilgiler sağlayabileceğini düşündük.

Olguların 1/3'üne çocukluk çağında tanı konulur, genellikle tip I ve IV formlarında görülür. Bu olgular sıklıkla tekrarlayan öksürük, pnömoni, dispne ve siyanoz ile semptom gösterir. ${ }^{4}$

Hastalığın kesin tanısı genellikle kitlenin cerrahi rezeksiyonu sonrası yapılan histopatolojik değerlendirme ile konur. Kitlenin büyüklüğüne göre uygulanan cerrahi teknik değişir.

Uygulanan cerrahi yöntemler; tek ya da multipl lobektomi, lobektomili ya da lobektomisiz tek veya multipl segmentektomi, anatomik olmayan rezeksiyon ve pnömonektomidir.?

Cerrahi tedavi kararı hastalığın semptomatik olup olmamasına bağIIdır. Semptomatik hastalarda cerrahi tedavi, tercihen lobektomi uygulanır. Illeri derece solunum sıkıntısı olan hastalarda cerrahi rezeksiyon hemen yapilır, ama az semptom gösteren ve yaşam fonksiyonunu etkilemeyen olgularda ileri yaşlarda yapılabilir. Büyük çocuklarda yapılan cerrahi tedavi, genellikle tekrarlayan enfeksiyonu önlemek ve malignite ile ilgili endişeleri gidermek için yapılır. Asemptomatik hastalarda ayrıca iki taraflı veya multifokal kistler ile aile öyküsü olan tüm hastalar için de cerrahi rezeksiyon önerilir. Üç-altı ayın ideal operasyon zamanı olduğu ileri sürülmüştür. Yenidoğan döneminde asemptomatik hastalara yapılan minimal invaziv cerrahi ile komplikasyon olmaksızın başarılı sonuçlar bildirilmiştir, en sık görülen komplikasyon tekrarlayan akciğer enfeksiyonudur. ${ }^{4}$ Olgumuza literatür bilgileri ışığında düzenli takiplerle birlikte 5 . ayında akciğer enfeksiyonları, sepsisi ve maligniteyi önlemek için cerrahi girişim planlandı.

Ayıııcı tanıda pulmonersekestrasyon, konjenital lober amfizem, konjenital pnömoni, diafragma hernisi, postinfeksi-๖yöz pnömotoseller, pediatrik pnömotoraks, plevral efüzyon ve hemotoraks düşünülmelidir.10Bizim hastamızın BTT sinde hava kistlerinden oluşan kistik görünüm izlendiği için CCAM tanısı konuldu. Amfizematöz görünüm izlenmediğinden konjenital lober amfizem dışlandı.

Sonuç olarak yenidoğan döneminde etyolojisi saptanamayan solunum sıkıntısı varlığında nadir gözükse de CCAM akılda tutulmalıdır. Hayatın ilk dönemlerinde çekilen PA akciğer filmi doğal olarak değerlendirilse bile kistlerin içinde sıvı olabileceğinden tanı dışlanamaz. Kist veya kistlerin oluşturacağı etki ve klinik duruma göre cerrahi tedavinin ne zaman yapılacağına karar verilmelidir. 


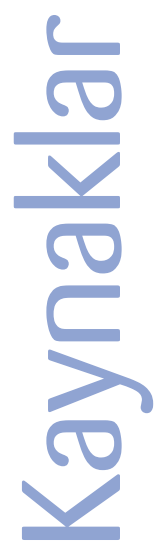

1. Van Dijk C, Wagenvoort CA. The various types of congeni-tal adenomatoid malformation of the lung. J Pathol 1973;110:131-4

2. Oh BJ, Lee JS, Kim JS, et al Congenital cystic adenomatoid malformation of the lung in adults: Clinical and CT evaluation of seven patients. Respirology 2006;11:496-501.

3. Hansen T, Cooper T, Weisman L. Congenital diseases affec- $\rightarrow$ ting the lung parenchyma. In contemporary diagnosis and management of neonatal respiratory diseases. Newton, PA: Handbooks in Health Care Co; 1995: 164-179.

4. Gülhan SŞE, Üstün LN.Akciğerin konjenital anomalileri.doi:10.5152/ tcb. 2012.32

5. Safak AA, Kunduracı E, Erdoğmuș B, ilıce Z,Yazıcı B.Congenital Cystic Malformation of The Lung: Case Report.Düzce Tıp Fakültesi Dergisi 2005; 1:24-26

6. Chikkannaiah $P$, Kangle R,Hawal M. Congenital cystic adenomatoid malformation of lung: Report of two cases with review of literature. Lung India. 2013 Jul-Sep; 30(3): 215-218.

7. Cacciari A, Ceccarelli PL, Pilu GL, Bianchini MA, Mordenti M, Gabrielli S, et al. A series of 17 cases of congenital cystic adenomatoid malformation of the lung: Management and outcome. Eur J Pediatr Surg 1997; 7:84-9.

8. Revillon $\mathrm{Y}$, Jan $\mathrm{D}$, Plattner $\mathrm{V}$, et al. Congenital cystic adenomatoid malformation of the lung: prenatal management and prognosis. J Pediatr Surg 1993; 28:1009-11.

9. Parikh D, Samuel M. Congenital cystic lung lesions: Is surgical Resection essential? Pediatr Pulmonol 2005;40:533-7.

10. Kumar A, Rathor DKS, Gupta A, Gupta VK, Padhya A.An Unusual Presentation of Congenital Cystoadenomatoid Malformation of Lung. Journal of Clinical and Diagnostic Research. 2017 May, Vol-11(5): PJ01-PJ02

11. Ch'in KY, Tang MY. Congenital adenomatoid malformation of one lobe of a lung with general anasarca. Arch Pathol (Chic). 1949;48:221-29

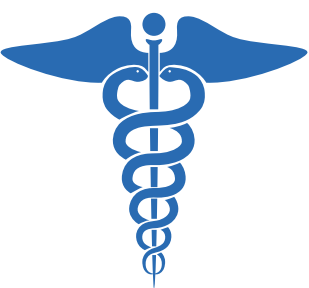

